\title{
Nutrient enrichment off Port Stephens: the role of the East Australian Current
}

\author{
Peter R. Oke ${ }^{\mathrm{a}, *}$, Jason H. Middleton ${ }^{\mathrm{b}}$ \\ ${ }^{a}$ College of Oceanic and Atmospheric Sciences, Oregon State University, 104 Ocean Administration Building, \\ Corvallis, OR 97331-5503, USA \\ ${ }^{\mathrm{b}}$ School of Mathematics, University of New South Wales, Sydney, Australia
}

Received 5 November 1998; received in revised form 11 August 1999; accepted 4 February 2000

\begin{abstract}
In January 1997, a bloom of the dinoflagellate Noctiluca scintillans occurred off Port Stephens, on the New South Wales (NSW) central coast. The nutrient enrichment that presumably caused the bloom was apparently unrelated to local winds. The purpose of this study is to investigate the role of the East Australian Current (EAC) in promoting nutrient-rich slope water into the euphotic zone off Port Stephens. To this end, a regional model of the NSW coast is presented and a new mechanism for upwelling is proposed. The simulations indicate that uplifting of slope water results from the interaction of the EAC with the continental shelf topography near Laurieton, located to the north of Port Stephens. The uplifted water is consequently advected along the shelf to Port Stephens, where the EAC separates from the coast. As a result of this divergence, the uplifted slope water is upwelled to the surface, and outcrops over the shelf. In situ velocity and temperature measurements are presented as evidence for the upwelling mechanism and the proposed path of the upwelled slope water is inferred by modelling the dispersal of a passive concentration tracer injected to the north of the upwelling region. The proposed upwelling mechanism may provide insight into topographically induced upwelling in other western boundary current regions. (C) 2001 Elsevier Science Ltd. All rights reserved.
\end{abstract}

Keywords: Coastal upwelling; Western boundary currents; Topographic effects; Algal blooms

\section{Introduction}

The purpose of this modelling study is to investigate the role of the East Australian Current (EAC) in promoting nutrient-rich slope water into the euphotic zone in the vicinity of Port

\footnotetext{
*Corresponding author. Tel.: + 1-541-737-2991.

E-mail address: proke@oce.orst.edu (P.R. Oke).
} 
Stephens $\left(32^{\circ} 40^{\prime} \mathrm{S}\right)$ on the central New South Wales (NSW) coast of Australia. This study is a component of the Ocean Nutrient and Phytoplankton Project (ONPP) coordinated by the NSW Environmental Protection Authority (EPA). One of the main objectives of the ONPP is to determine the key physiochemical processes that control algal bloom activity in the NSW coastal waters. In January 1997, a Noctiluca Scintillans bloom occurred off Port Stephens (Ajani et al., 2000). Port Stephens is a site of frequent algal blooms (Hallegraeff and Jeffrey, 1993). The coastal circulation near this location is dominated by the southward flowing EAC that is highly energetic in this region, with currents of up to $2 \mathrm{~m} \mathrm{~s}^{-1}$ flowing adjacent to the shelf break (Church and Cresswell, 1986). Furthermore, the EAC tends to separate from the coast at this location (Godfrey et al., 1980b), a factor that is shown to be important in the nutrient enrichment of coastal waters. As such, the two factors that are most likely to aid nutrient enrichment include the effects of local winds and the influence of the EAC. The latter of these is investigated using a three-dimensional, regional primitive equation ocean model of NSW coastal waters with an experimental design similar to that of Gibbs et al. (1997). The model is used to simulate a two-week period during January 1997 when the aforementioned Noctiluca bloom developed. The synoptic details of the model simulation are verified against sea surface temperature (SST) data and temperature data from a depth of $250 \mathrm{~m}$ (T250).

The usefulness of passive tracer experiments that was demonstrated in an epic study by England (1995) is utilised to investigate the temporal evolution of potentially nutrient-rich slope water that originated to the north of Port Stephens. This experiment demonstrates the persistence of EACdriven upwelling and the importance of the separation of the EAC from the coast. Previously, Tranter et al. (1986) observed the multiple separations of the EAC along the north coast of NSW with correspondingly high levels of chlorophyll biomass over the shelf. These observations indicate that the divergence of the EAC from the coast is likely to promote nutrient enrichment of NSW coastal waters. Similar characteristics are evident in the SST image from the NOAA-11 satellite, presented in Fig. 1, showing the divergence of the EAC from the coast with a corresponding upwelling off Laurieton. Although this image does not correspond to the event in question here, it demonstrates the typical surface signature of the Cape Byron upwelling that was investigated by Oke and Middleton (2000) and Laurieton upwelling that is being investigated here.

In the vicinity of Port Stephens, there are several significant topographic irregularities including Smoky Cape, Laurieton and Sugarloaf Point. The effects of these irregularities may result in upwelling through the mechanism proposed by Oke and Middleton (2000), who showed that the Cape Byron upwelling (denoted in Fig. 1) is topographically induced. This mechanism describes how the alongshore advective acceleration of the EAC over a narrowing continental shelf accelerates the near bottom currents resulting in an area of persistent high bottom stress. This high bottom stress results in enhanced vertical mixing which in turn reduces the local stratification and hence the Burger number in the BBL. Low Burger number flow has a relatively long shutdown time (Garrett et al., 1993) which means that, on time scales for which the EAC is quasisteady (1-2 weeks), the BBL does not shut down and remains energetic, transporting cold, nutrient-rich water onto the inner-shelf. Such a shutdown would normally be expected to make EAC-driven upwelling inefficient, as was shown by Gibbs et al. (1998) for the Sydney region.

It is shown in this study that the interaction of the EAC with the shelf topography, coupled with the separation of the EAC from the coast, probably caused an upwelling that resulted in the 


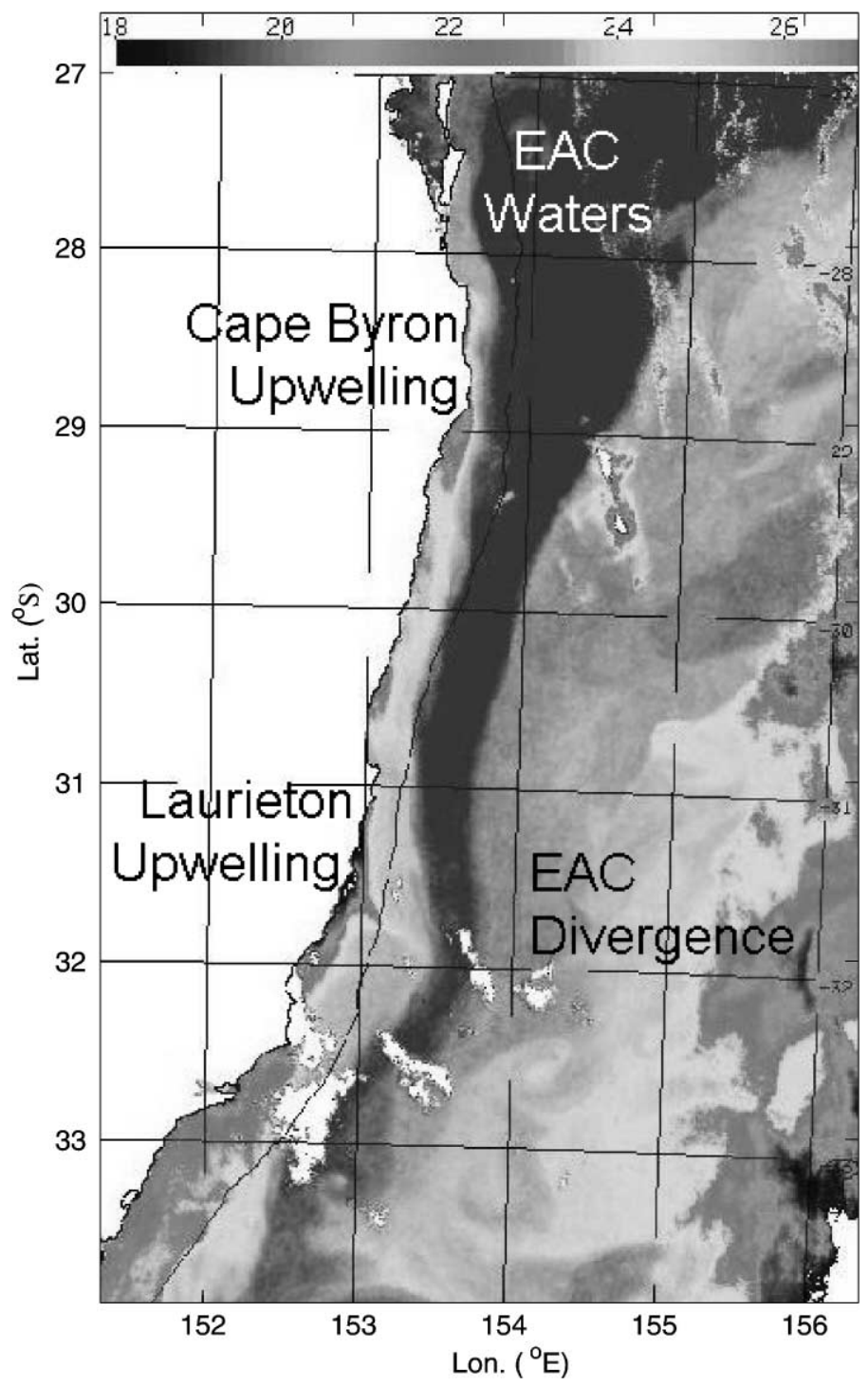

Fig. 1. NOAA-11 SST image of the NSW coast for November 18, 1993 showing the surface signature of Cape Byron upwelling and Laurieton upwelling.

Noctiluca bloom off Port Stephens in January 1997. This mechanism for upwelling may provide insight into upwellings in other western boundary current regions such as the Gulf Stream, the Kuroshio Current, the Brazil Current and the Aghulas Current, where alongshore topographic irregularities exist. In this paper, details of the model configuration are presented in Section 2 followed by the results and an analysis in Sections 3 and 4, respectively. A concentration tracer experiment is presented in Section 5 followed by supporting evidence from observations in Section 6 and the conclusions in Section 7, including a schematic of the proposed upwelling mechanism. 


\section{Model configuration}

The model that is configured is the Princeton Ocean Model (POM). For an in-depth description of the model equations and the numerical techniques, the reader is referred to Blumberg and Mellor (1987). The model configuration is similar to that presented by Gibbs et al. (1997), who illustrated how baroclinic instabilities off Jervis Bay, on the NSW south coast, can result in the uplifting of sub-surface water into the euphotic zone, explaining a massive algal bloom that impacted the Bay in 1992.

The model domain extends between the latitudes of $28^{\circ} 30^{\prime} \mathrm{S}$ and $37^{\circ} 30^{\prime} \mathrm{S}$ and the longitudes of $150^{\circ} \mathrm{E}$ and $158^{\circ} \mathrm{E}$ (Fig. 2). The horizontal, orthogonal, curvilinear grid was generated using the method developed by Haidvogel et al. (1991) and consists of $50 \times 74$ points with cross-shore grid spacings of $2.5-16 \mathrm{~km}$ and alongshore grid spacings of 5-22 km. These grid spacings are greatest near the open boundaries in order to minimise the unwanted boundary effects. The vertical grid consists of $31 \sigma$-levels concentrated over the upper and near-bottom depths in order to adequately resolve the respective boundary layers. The bathymetry was interpolated from the ETOPO5 data set (NOAA, 1988) with a minimum depth of $50 \mathrm{~m}$ in order to avoid numerical instabilities on the shelf. The constraint on the barotropic and baroclinic time steps, that are 8.5 and $300 \mathrm{~s}$, respectively, is reduced by setting the maximum depth to $2000 \mathrm{~m}$. This feature does not significantly influence the model circulation since it has previously been observed that at this depth, the currents are very small and incoherent with the surface currents (Boland and Hamon, 1970). Simulations with a maximum bottom depth of $5000 \mathrm{~m}$ were run, and the model circulation was insensitive to this factor. The effects of pressure gradient errors due to the $\sigma$-coordinates over

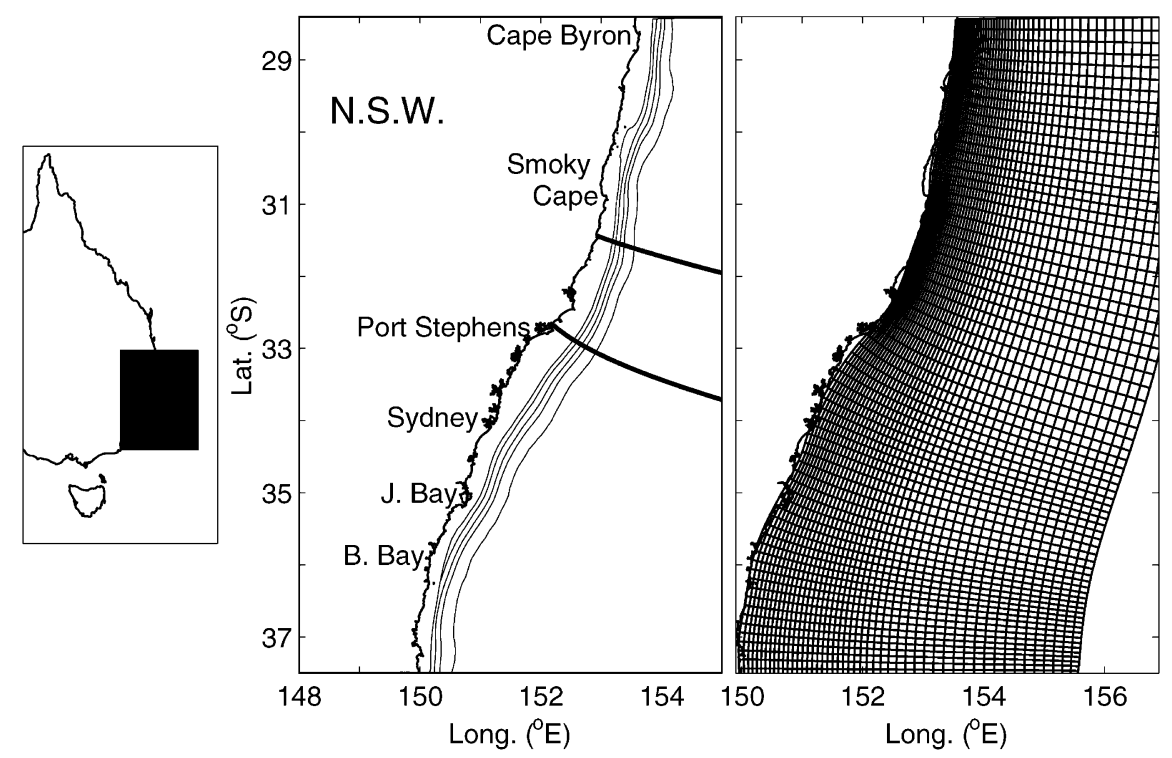

Fig. 2. Location of the study area (left) off South Eastern Australia. Model bathymetry showing the 250, 500, 1000, 1500 , and $2000 \mathrm{~m}$ isobaths (middle) and the model grid (right). The locations of the transects displayed in Figs. 9 and 10 are also denoted. 
a sloping bottom were considered by running an unforced test case with no horizontal density variations and zero initial velocity. Under these conditions, any velocities that are generated are considered to be errors. This test demonstrated that these velocities are small compared to the currents of interest.

A combination of radiation, zero gradient and relaxation conditions are implemented at the southern and eastern boundaries, as described in Gibbs et al. (1997) that are effective at allowing disturbances to propagate out of the model domain whilst relaxing the boundary fields to their initial state (Orlanski, 1976; Blumberg and Kantha, 1985; Palma and Matano, 1998). This relaxation is a necessary, yet limiting characteristic of the model configuration, since in reality, the boundary fields are generally expected to change slowly due to forcing from outside the model domain.

The main forcing for the model is the lateral boundary forcing imposed at the northern boundary where all model variables are clamped to their initial values, providing a constant inflow that is representative of the EAC with a baroclinic, southward jet flowing adjacent to the shelf break. No additional surface forcing is included, allowing an idealised investigation of the role that the EAC plays in the upwelling of slope water to be undertaken.

The initial temperature field is constructed from the available SST and T250 data. This data is available in weekly averages from the Royal Australian Navy (RAN). Based on a combination of the Levitus (1982) climatological temperatures, SST and T250 data, a vertical profile of temperature is extrapolated over the entire water column. Having initialised the temperature fields, the salinity is consequently initialised from a temperature-salinity relationship that is valid for the Tasman Sea (Pearce, 1983). Subsequently, the density field is calculated from the nonlinear equation of state (Mellor, 1991).

An initial approximation of the barotropic fields is established by calculating the dynamic height of the water column (Pearce, 1983). These fields, as well as the baroclinic currents are then refined by the model by executing a diagnostic simulation for 2 days, effectively providing a nowcast for the initial state. During this initial model spin up, the baroclinicity of the density field is ramped up smoothly, in order to determine the baroclinic currents. The model is then run prognostically, where all of the model variables are allowed to evolve, providing a forecast for the ocean circulation. The simulation presented below is not an attempt to replicate all the details of the regional circulation during January 1997, rather the comparison with data is made to ensure that the simulated circulation is representative of the EAC region for the period considered.

\section{Results}

On the first day of the prognostic simulation, a narrow EAC jet is evident in both the SST and T250 data adjacent to Smoky Cape (Fig. 3). The Tasman front, denoted by the $15^{\circ} \mathrm{C}$ isotherm in the T250 field, extends from the coast at Port Stephens eastwards and a warm-core eddy is also present to the east of Jervis Bay. Because of the dynamic (non-zero) nature of the model initialisation, when the prognostic simulation begins, the initial fields experience a period of adjustment. Consequently, the initial fields were adjusted for repeat simulations in order to suitably "tune" the initialisation for the period of interest.

During the first week of simulation, a branch of the EAC spread along the NSW coast adjacent to the $300 \mathrm{~m}$ isobath. By January 19th, four days into the prognostic simulation, warm water has 

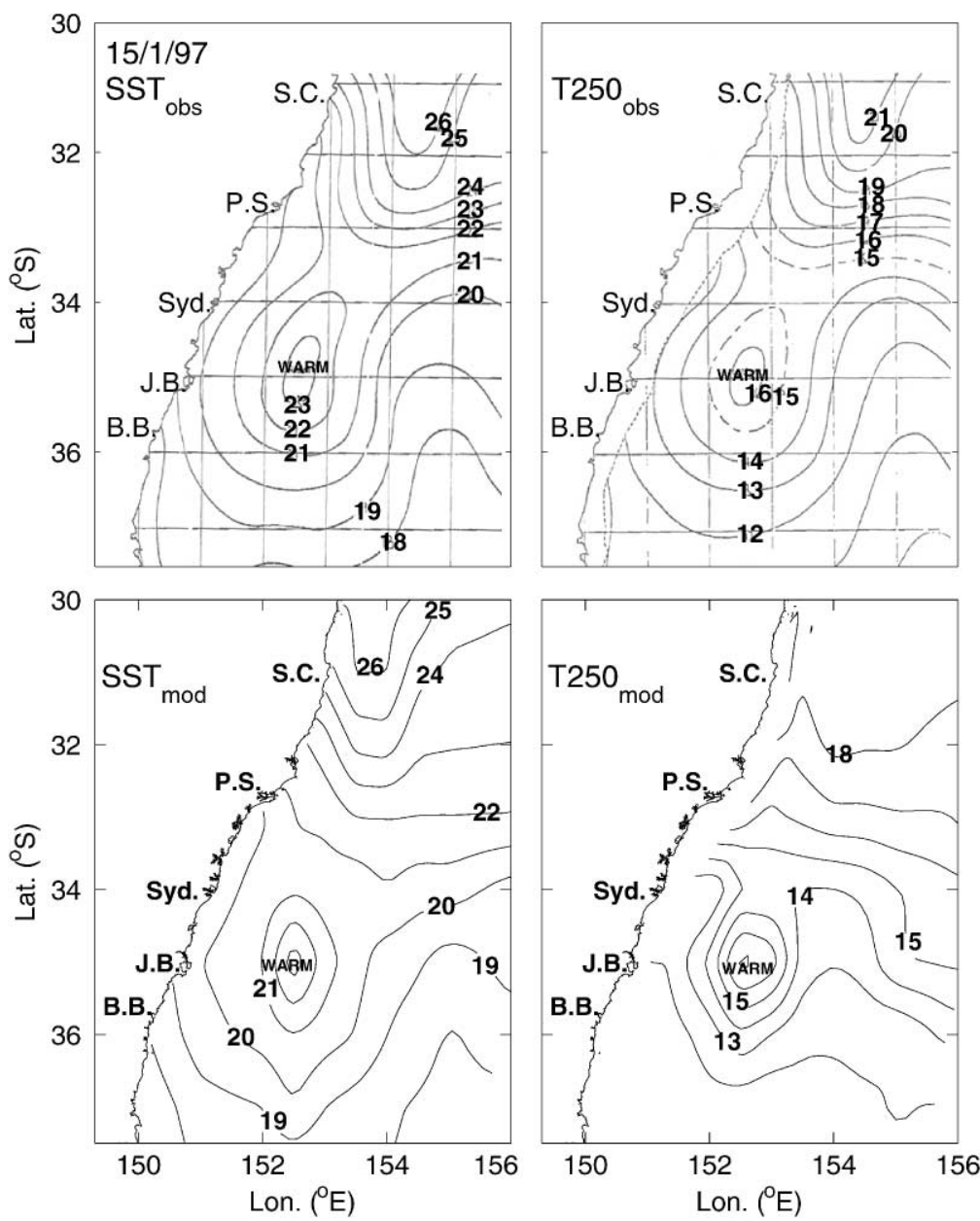

Fig. 3. Observed (top) and modelled (bottom) SST (left) and T250 (right) fields valid for 15 January, 1997. The position of Smoky Cape (S.C.), Port Stephens (P.S.), Sydney (Syd.), Jervis Bay (J.B.) and Batemans Bay (B.B.) are indicated.

spread along the coast to as far south as Jervis Bay (Fig. 4). This feature of the circulation is evident in both the modelled and observed SST fields; however, the observed SST's indicate a thinner "tongue" of warm water along the coast.

During the second week, the warm EAC water encompassed the warm-core eddy that resided off Jervis Bay, bringing warm water as far south as Batemans Bay (Fig. 5). The modelled SST structure is very similar to the RAN SST chart with both indicating that the southward penetration of the EAC water has subsided, with the SST structure exhibiting a seaward and shoreward tongue off Batemans Bay. The modelled and observed T250 fields are also similar, indicating that warm EAC water has been advected as far south as Jervis Bay. Overall, the similarity between the modelled and observed fields indicates that the modelled circulation is representative of the conditions during January 1997. 

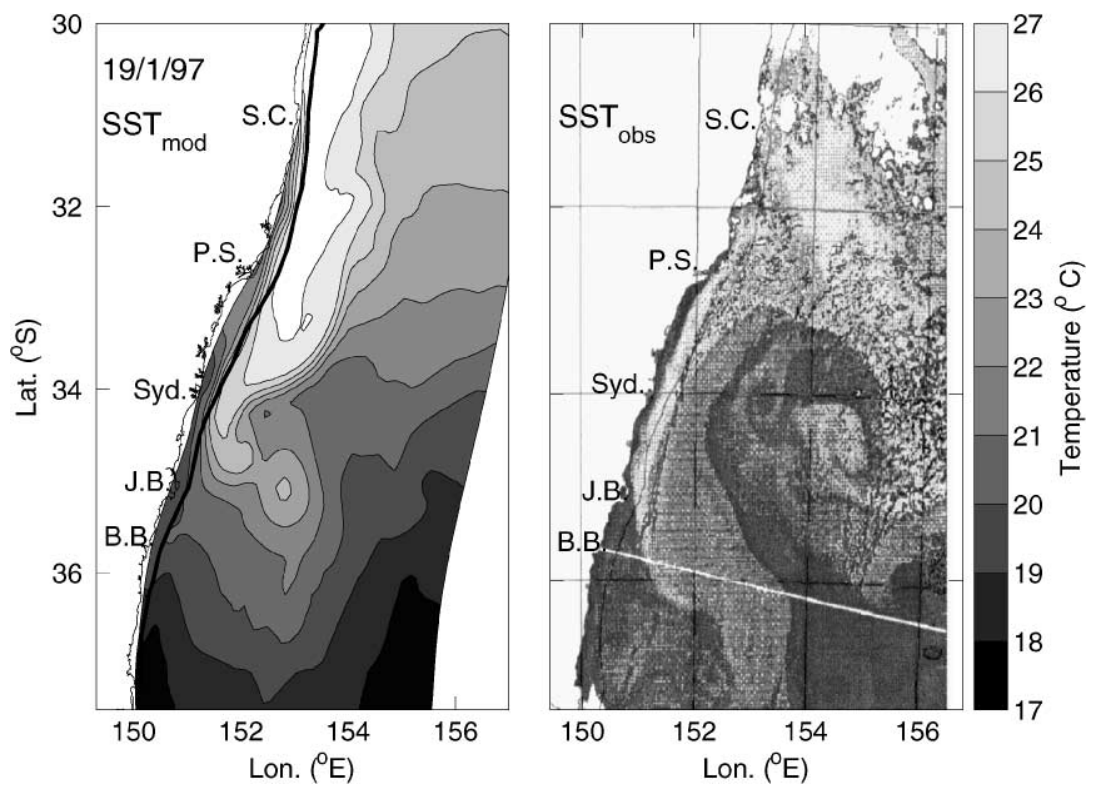

Fig. 4. Modelled (left) and observed (right) SST fields valid for 19 January, 1997.

In terms of upwelling off the NSW coast, the temperature field near Port Stephens is decreased over the continental shelf during the simulation. Similarly, at $250 \mathrm{~m}$ depth the temperature decreased from 17 to $14^{\circ} \mathrm{C}$ during this period. It is not clear whether this decrease in temperature is due to upwelling or an increase in baroclinicity during the model spin up. This aspect of the circulation is further investigated in Section 4.

\section{Analysis}

An examination of the alongshore bottom stress fields during the simulation indicates that there is an area of high, positive, alongshore bottom stress in the vicinity of Smoky Cape and Laurieton throughout the simulation (Fig. 6). Alongshore Bottom stress $\tau_{\mathrm{B}}$ is given by

$$
\tau_{\mathrm{B}}=\rho_{0}^{-1} C_{\mathrm{D}} v_{\mathrm{B}}\left|v_{\mathrm{B}}\right|,
$$

where $\rho_{0}$ is a reference density, $C_{\mathrm{D}}$ is the bottom drag coefficient, $v_{\mathrm{B}}$ is the alongshore bottom velocity and $\left|v_{\mathrm{B}}\right|$ is the magnitude of the bottom velocity. Positive bottom stress indicates a stress in the northward direction that is opposing the southward flowing current. The persistent, high bottom stress indicates that the BBL shutdown process (MacCready and Rhines, 1993) is inhibited. The depth-integrated, alongshore currents near Laurieton indicate that there is a region of very strong currents between Smoky Cape and Port Stephens (Fig. 7). These features of the continental shelf circulation are consistent with the mechanism proposed by Oke and Middleton (2000), where the narrowing of the continental shelf results in an advective acceleration of the current that drives an upwelling BBL. The shelf width and cross-sectional area are plotted as a function of latitude in Fig. 8 showing the narrowing of the continental shelf off Smoky Cape. We 

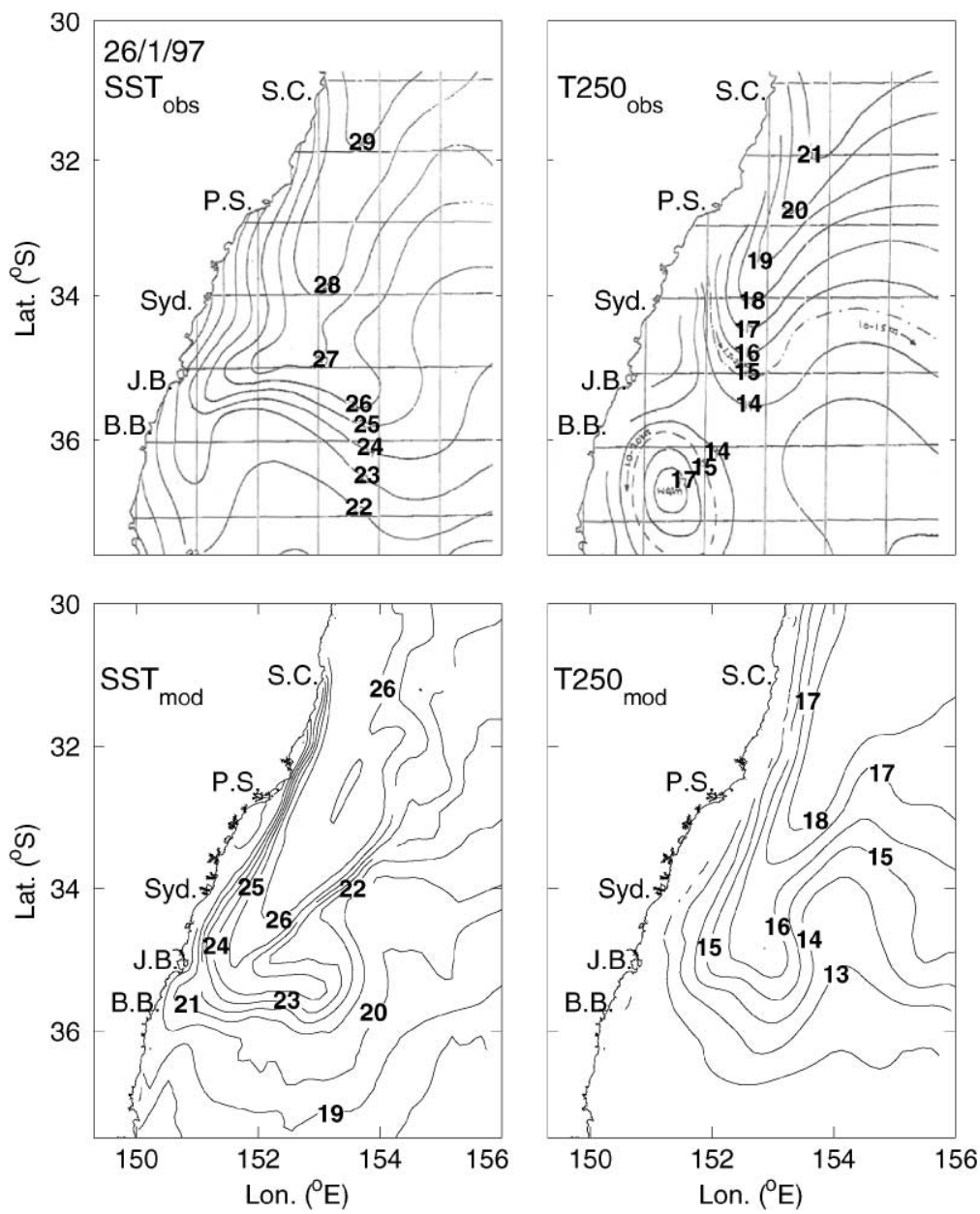

Fig. 5. Observed (top) and modelled (bottom) SST (left) and T250 (right) fields valid for 26 January, 1997. The position of Smoky Cape (S.C.), Port Stephens (P.S.), Sydney (Syd.), Jervis Bay (J.B.) and Batemans Bay (B.B.) are indicated.

suggest that the narrowing of the continental shelf off Smoky Cape is causing the EAC to accelerate, resulting in stronger near-bottom currents, and consequently high, persistent bottom stress. This idea was first suggested by Rochford (1975) to explain observed upwelling off Laurieton which were unrelated to local winds.

The evolution of the baroclinic fields near Laurieton $\left(31^{\circ} 30^{\prime} \mathrm{S}\right)$, located approximately $130 \mathrm{~km}$ north of Port Stephens, shows the vertical excursions of isotherms over the shelf (Fig. 9). This figure shows the $20^{\circ} \mathrm{C}$ isotherm being uplifted to a depth of $50 \mathrm{~m}$ from the start of the simulation to January 25, 10 days into the simulation, after which time, this isotherm is suppressed, moving back to a depth of around $100 \mathrm{~m}$. The maximum speed encountered in the alongshore current also occurred on the $25 \mathrm{th}$, when the speed exceeded $1.8 \mathrm{~m} \mathrm{~s}^{-1}$. Throughout the simulation, the EAC jet is centred very close to the shelf break. Moreover, the fact that the maximum alongshore current coincided with the strongest uplifting supports the argument that the acceleration of the EAC, in 

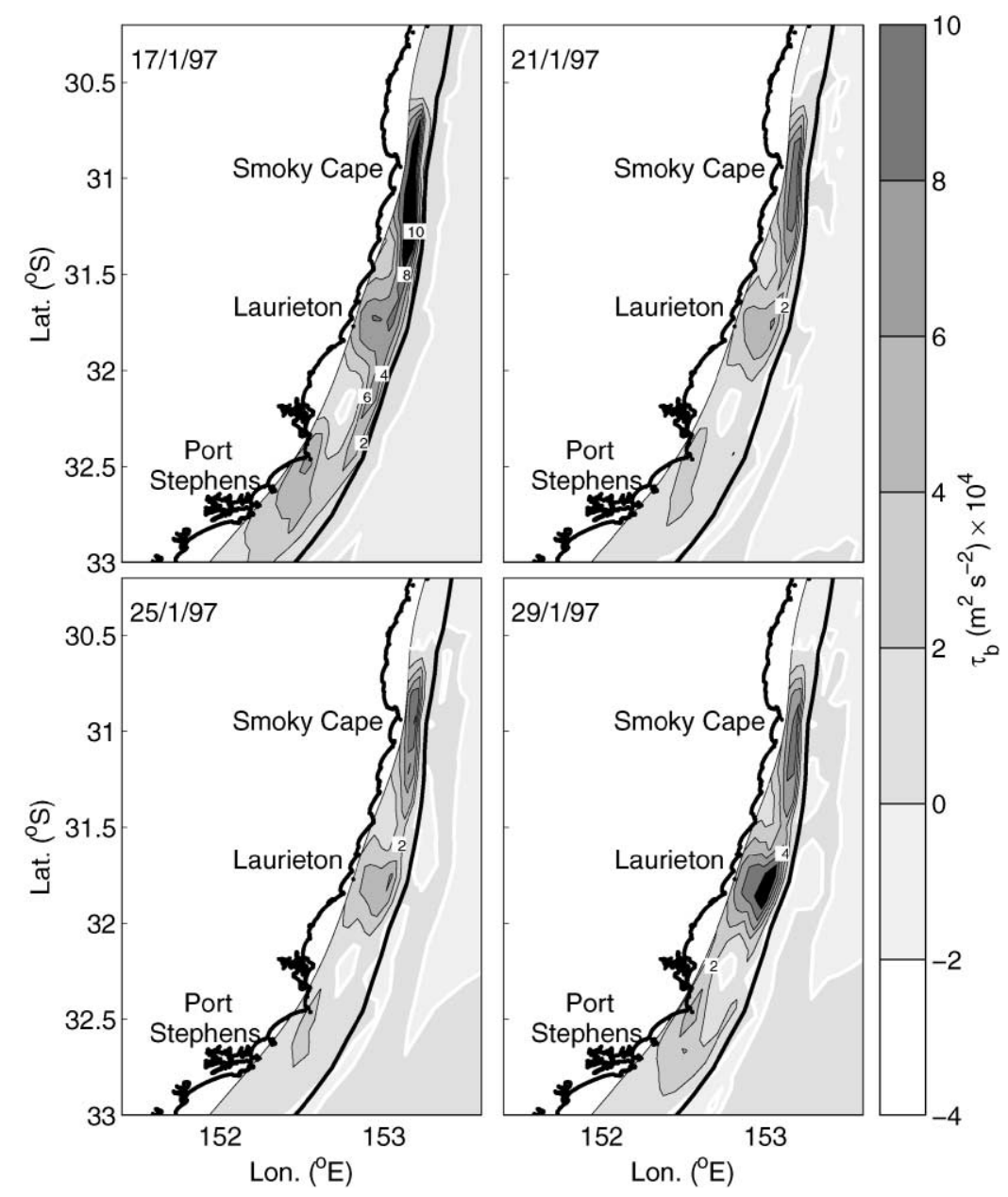

Fig. 6. Alongshore bottom stress fields in the vicinity of Port Stephens.

response to the alongshore topographic variations, results in shoreward bottom Ekman transport that effectively uplifts slope water onto the shelf. Persistent shoreward currents were evident between the coast and the $200 \mathrm{~m}$ isobath just above the seabed. Whilst the nearshore isotherms off Laurieton are not being upwelled in the later part of the simulation, an onshore transport is still maintained. This feature is again consistent with the results of Oke and Middleton (2000), indicating that the cold upwelled water and the warm interior water are being vertically mixed above the shelf topography.

The slope of the isotherms over the shelf are very close to the slope of the bottom topography which is a characteristic that was evident in the temperature observations made by Rochford (1975) off Laurieton during several upwelling events. In light of this, one could argue that slope water could be actively transported from beyond the shelf break onto the shelf and onto the innershelf, leaving no trace in the temperature field. Also, the temperature of the water to the north of Laurieton is warmer; therefore, its alongshore advection may be encompassing the upwelled 

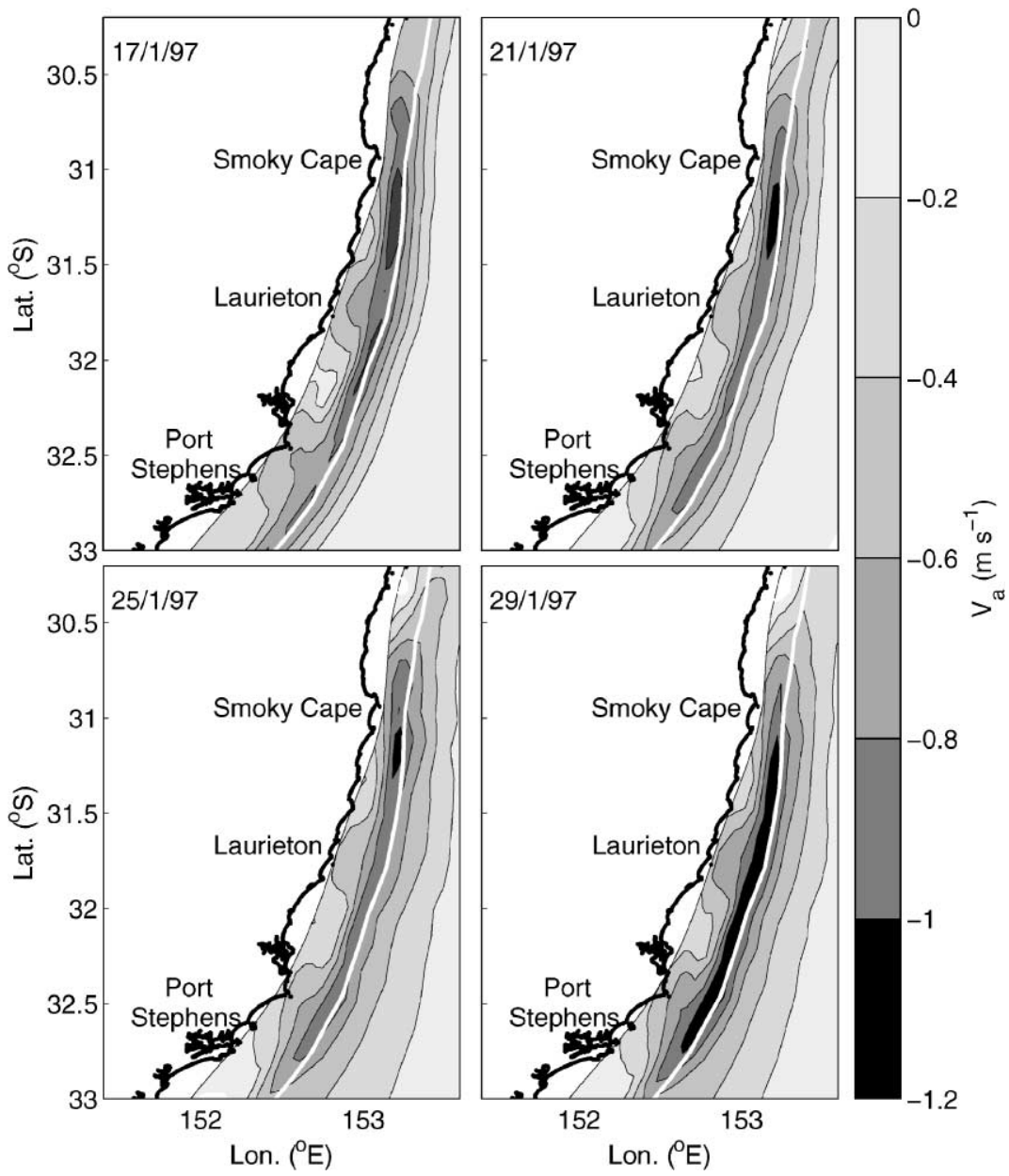

Fig. 7. Depth-integrated alongshore currents in the vicinity of Port Stephens.

water. This suggestion is further investigated in the concentration tracer experiment presented in Section 5 which shows that uplifting off Laurieton is persistent throughout the simulation.

We suggest that the persistent shoreward transport induced by the high bottom friction is effective at transporting potentially nutrient-rich water onto the shelf. Once on the shelf, the slope water is likely to be advected southwards by the strong shelf currents between Smoky Cape and Port Stephens. This suggestion is again consistent with the observations of Rochford (1975), who showed the distribution of the upwelled water to extend along the shelf to the south of Smoky Cape for some distance.

The baroclinic fields off Port Stephens (Fig. 10) indicate that the $20^{\circ} \mathrm{C}$ isotherm is upwelled to the surface off Port Stephens by January 23. This transect is approximately $130 \mathrm{~km}$ to the south of Laurieton, where slope water with a temperature of $20^{\circ} \mathrm{C}$ is being uplifted onto the continental shelf. The cross-shore currents indicate a strong offshore transport near the surface with speeds in excess of $0.3 \mathrm{~m} \mathrm{~s}^{-1}$. This is indicative of the divergence of the EAC from the coast. This divergence 

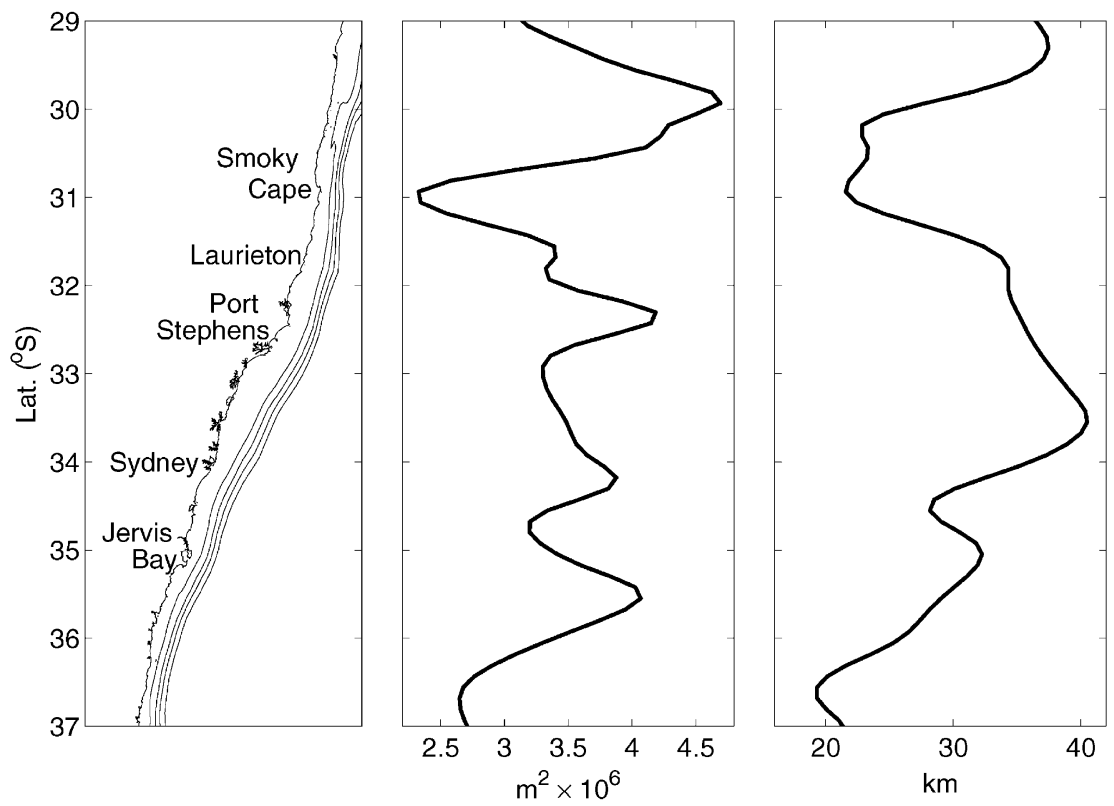

Fig. 8. NSW coastline and topography (left); cross-sectional area between the coast and the $300 \mathrm{~m}$ isobath (middle) and the shelf width (right) as a function of latitude.

is most intense near the surface. Additionally, the core of the EAC is located beyond the shelf break, unlike the transect presented off Laurieton (Fig. 9). The seaward currents associated with this divergence are responsible for advecting the near surface isotherms offshore. This type of cross-shore adjustment of the EAC is reminiscent of the observations of Tranter et al. (1986) in the same region, where offshore surface transport is compensated by a weak, shoreward transport over the shelf (below the zero contour). Thus, we suggest that the potentially nutrient-rich slope water that is uplifted near Laurieton is upwelled to the surface (euphotic zone) off Port Stephens as a result of the EAC's separation from the coast.

\section{Concentration tracer experiment}

In order to further investigate the feasibility of the proposed upwelling mechanism and to gain insight into the model circulation, the dispersal of slope water is examined by considering the evolution of a passive concentration tracer (England, 1995). The tracer is initialised and imposed thereafter at $100 \%$ over the bottom $5 \sigma$-levels off Smoky Cape between the 200 and $600 \mathrm{~m}$ isobaths. The tracer is then advected and diffused in an analogous fashion to temperature and salinity. Although the tracer remains passive throughout the simulation, there can be problems with the inclusion of such a tracer, mainly due to the limitations of the advection scheme within the POM which is known to have unrealistic computational modes. The non-zero tracer values are imposed with a smooth Gaussian structure in order to reduce the effects of the computational modes on the tracers advection. These effects are still evident, however, by the fact that, in the presence of a southward current, some non-zero tracer values appear to propagate northwards. 


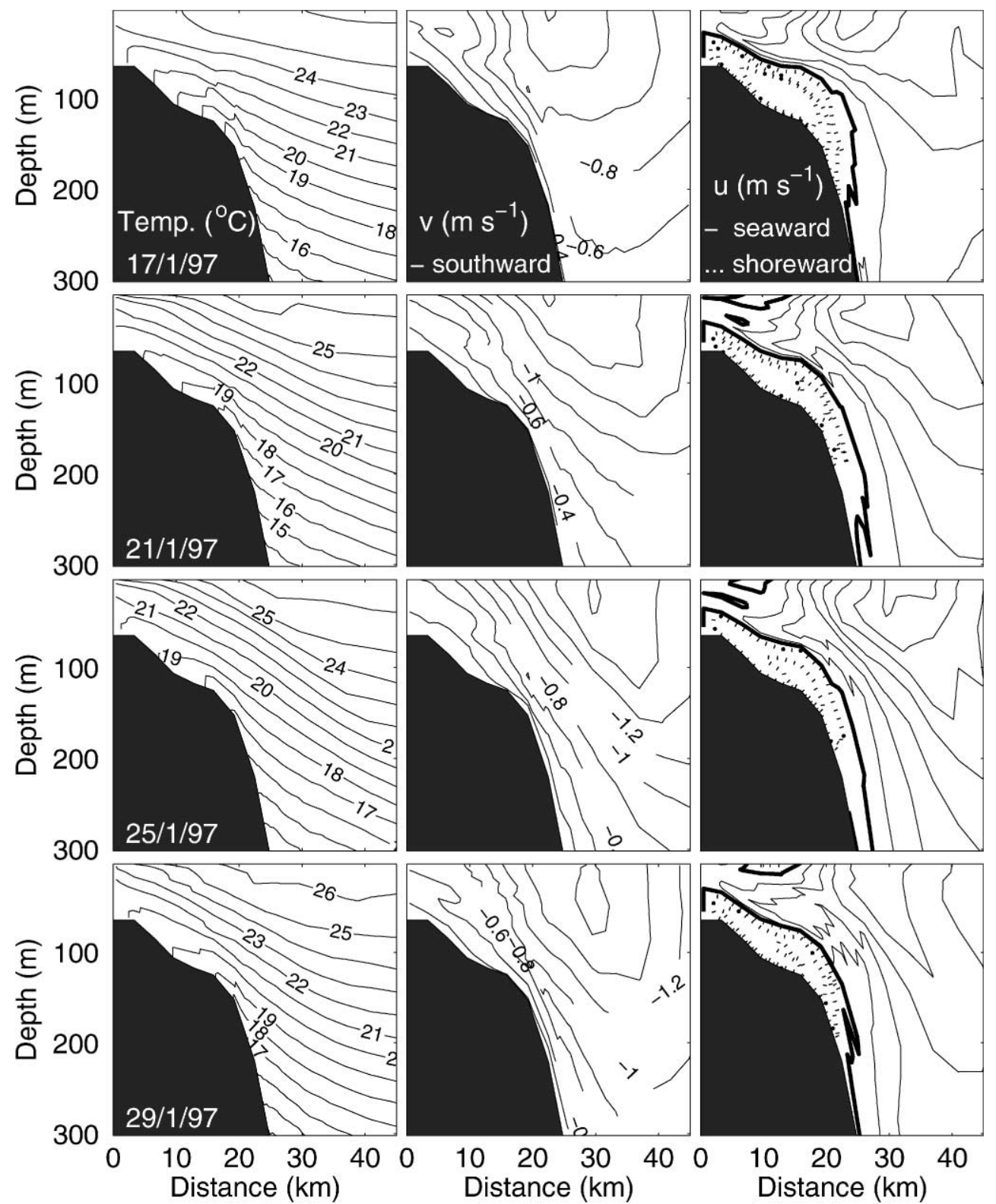

Fig. 9. Contour plots of temperature (left, $\Delta T^{\circ}=1^{\circ}$ ), alongshore currents (middle, $\Delta v=0.2 \mathrm{~m} \mathrm{~s}^{-1}$ ) and cross-shore currents (right, $\Delta u=0.05 \mathrm{~m} \mathrm{~s}^{-1}$, the thick line indicates the zero contour), off Laurieton. The location of the transect is displayed in Fig. 2.

Additional improvements could be obtained by increasing the order of the advection scheme and including a constraining limiter in the scheme (Leonard et al., 1995); however, this would require major alterations to the model code to improve the numerics and is not the focus of this research.

The tracer is reinitialised to zero every three days throughout the domain, with the exception of the input region off Smoky Cape in order to assess the temporal behaviour of the upwelling. The 


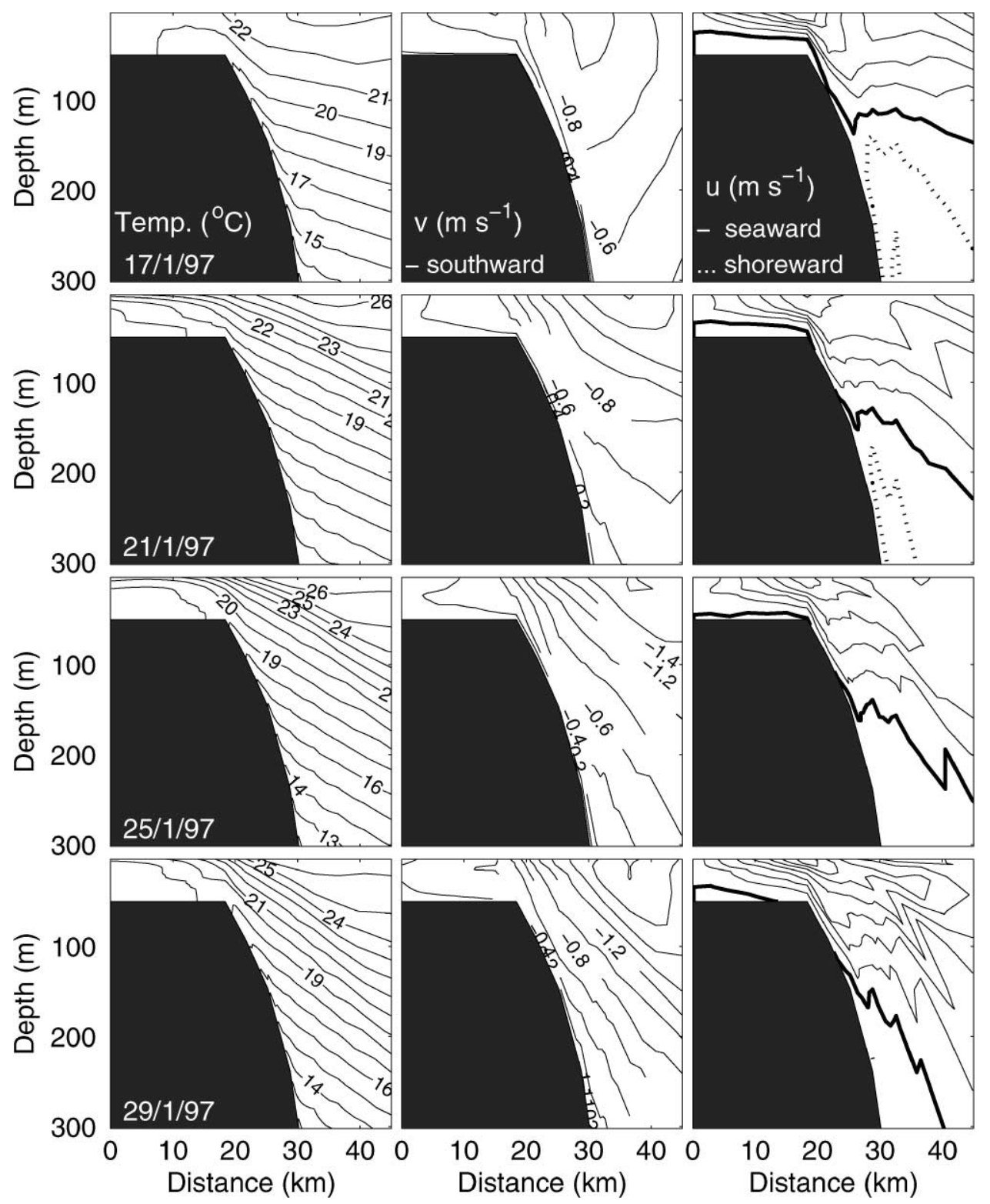

Fig. 10. As for Fig. 9, except off Port Stephens.

time evolution of the concentration tracer at a near bottom $\sigma$-level indicates that slope water is promoted onto the shelf between Smoky Cape and Laurieton (Fig. 11) and is consequently advected southwards, as suggested in Section 4. A steady uplift of the tracer onto the shelf is evident throughout the simulation.

The upwelling of slope water to the surface off Port Stephens is investigated through consideration of a near surface $\sigma$-level (Fig. 12), which indicates that the slope water was being 


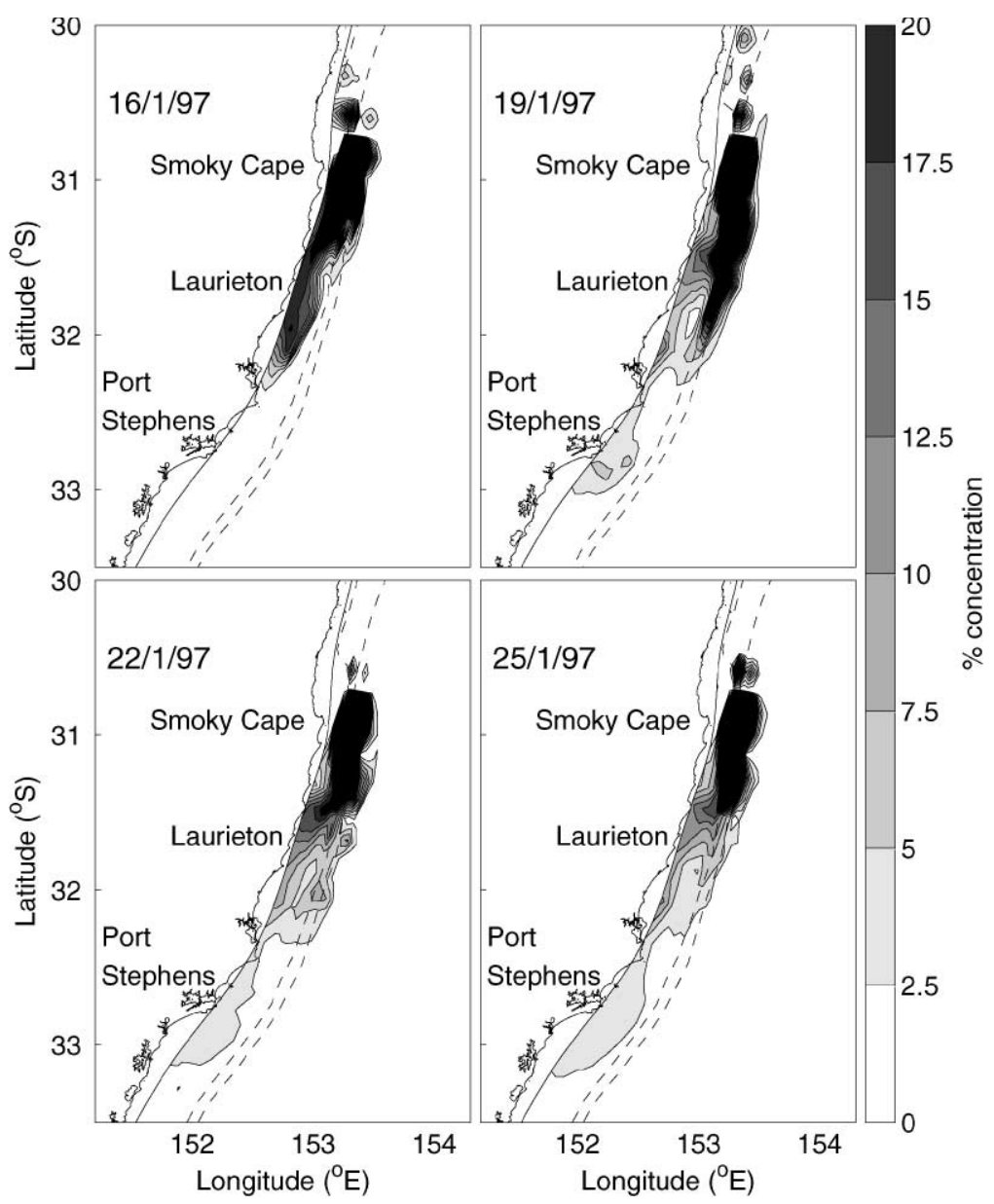

Fig. 11. Contour plots of a concentration tracer presented as a percentage of the initial concentration initialised off Smoky Cape showing the projected path of slope water along a near bottom $\sigma$-level $(\sigma=-0.992)$.

upwelled between Laurieton and Port Stephens. The near surface distribution of the tracer is remarkably consistent with the distribution of the upwelled water off Laurieton in the SST image presented in Fig. 1, giving confidence in the validity of the model circulation. This location is consistent with the inferences made above from the baroclinic fields. The distribution of the concentration tracer is isolated to the inner-shelf off Laurieton and is dispersed further offshore as it moves southwards. This is probably due to entrainment in the mean EAC flow due to vertical mixing as a result of the EAC's interaction with the continental shelf topography as described in Oke and Middleton (2000). Such entrainment has previously been inferred by observations off the NSW coast to explain the incidence of high nutrient levels that coincided with the encroachment of EAC eddies off Sydney (e.g. Tranter et al., 1986; Cresswell, 1994). 


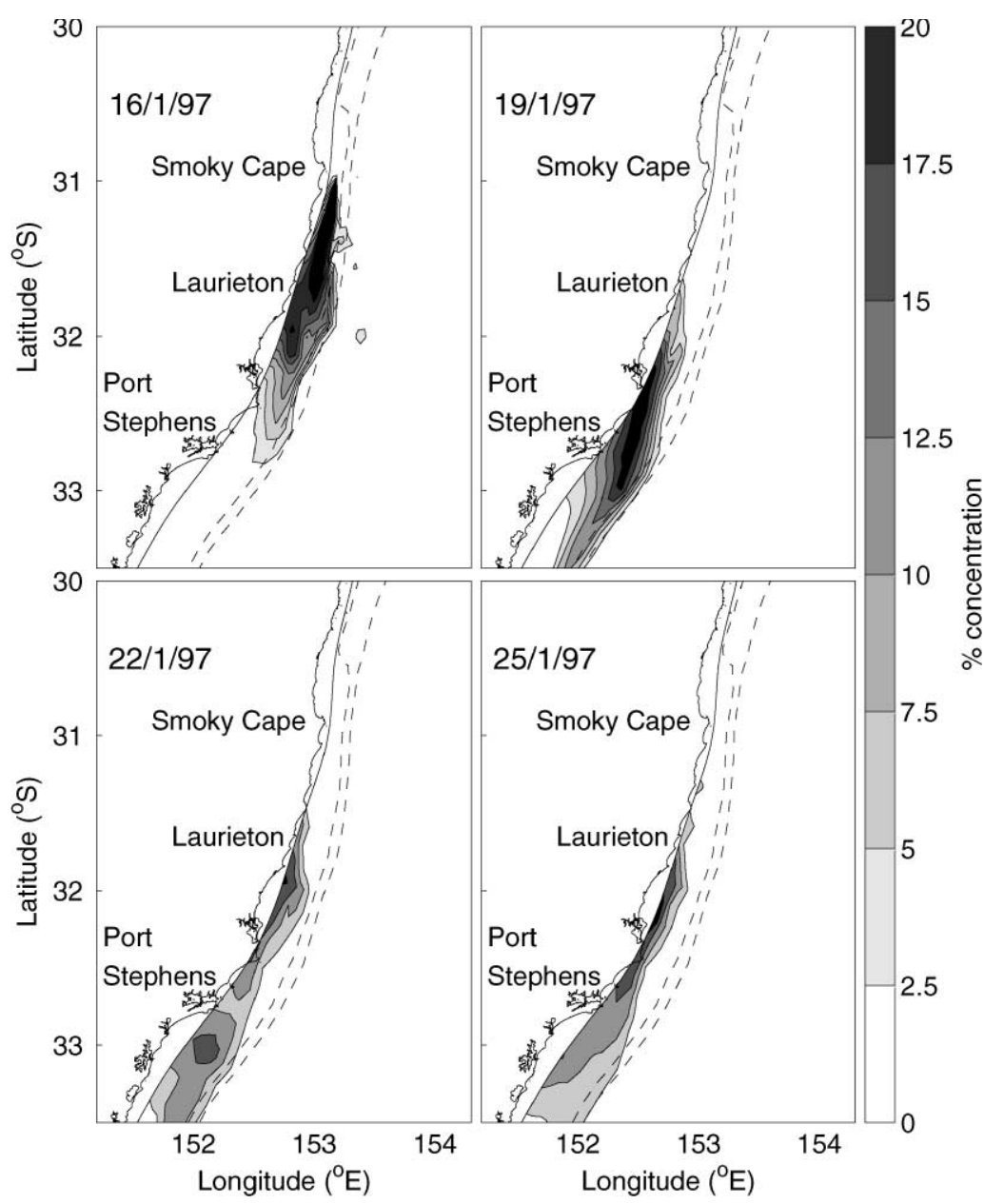

Fig. 12. As for Fig. 11, except along a near surface $\sigma$-level $(\sigma=-0.109)$.

\section{Observational evidence}

A time series of temperature and currents at a depth of $55 \mathrm{~m}$ in $60 \mathrm{~m}$ of water from near Port Stephens (located along the transect considered in Fig. 10) during January 1997 (Ajani et al., 2000) is shown in Fig. 13. Also presented are 3 hourly wind observations from the Port Stephens region. The current and wind time series are aligned so that the direction of the alongshore components are in the direction of the principal axis of the data $\left(11^{\circ} \mathrm{N}\right)$.

We suggest that there are two dominant factors that caused the temperature variations in the observed time series. The first is local wind forcing, indicated by the dotted lines (Fig. 13). Two out of the three obvious wind-driven events are strong downwelling events, resulting in a temperature increase over the inner-shelf due to the shoreward advection of warm EAC water. The third is a weak, short-lived upwelling event, following January 27, when the nearshore 


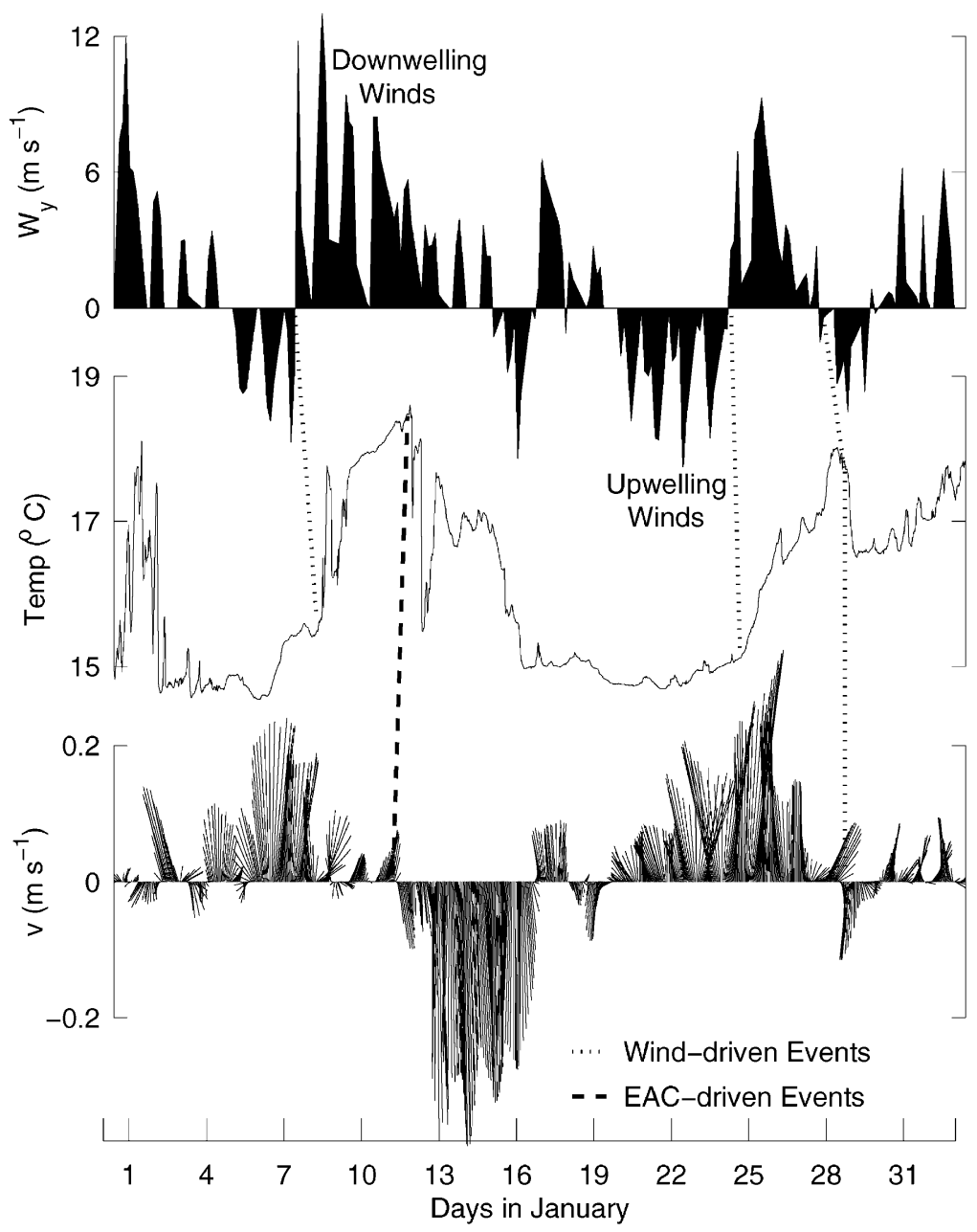

Fig. 13. Observed 3 hourly alongshore winds (top), temperature (middle) and currents (bottom) at $55 \mathrm{~m}$ depth in $60 \mathrm{~m}$ of water from near Port Stephens during January 1997.

temperature drops by about $1.5^{\circ} \mathrm{C}$. The second factor is the effect of the EAC. On January 12 , the alongshore current increased to the south. This increase is apparently unrelated to the local winds, and is therefore interpreted as an intrusion of the EAC. Since the measurements are taken within a few kilometres of the coast, this acceleration is interpreted as the shoreward edge of the EAC. The nearshore temperature clearly drops by $4^{\circ} \mathrm{C}$ over the next week. It appears that the temperature decrease is the result of a shoreward bottom Ekman transport beneath the strong, unsteady EAC either at the current meter site, or to the north of it. Over the next week or so the currents weaken, and change direction, flowing to the north. In the absence of northward winds around January 20 , it seems as if this northward flow is not wind-driven. The northward current may be associated with either remotely forced coastal trapped waves or a northward countercurrent that has been observed to flow over the inner-shelf when the EAC diverges, or separates from the coast (e.g., 
Godfrey et al., 1980a); however, the paucity of observations limits the clarification of this suggestion. The cooler waters are maintained over the inner-shelf indicating that the source of the upwelling is maintained during this time, possibly due to a constant supply of slope water through the upwelling mechanism presented in Section 4. The precise cross-shore position of the EAC during this period is not known, however the simulations indicate a divergence at this time that is consistent with the interpretation given above.

Observations that are similar to those presented in Fig. 13 have previously been made to the south of Port Stephens (Tranter et al., 1986, their Fig. 11). The source of the slope water intrusion was attributed to peripheral currents associated with the EAC eddy field, which was shown to be very dynamic at that time. However, the upwelling mechanism proposed in this study may provide an alternative explanation for Tranter et al.'s observations.

\section{Conclusions}

This study has revealed how alongshore topographic variations near Laurieton cause a local acceleration of the EAC over the narrowing continental shelf, resulting in a region of high bottom stress beneath the strengthened currents. This bottom stress is shown to drive an energetic BBL, uplifting slope water onto the shelf. The origin of the upwelled water appears to be at a depth of about $200 \mathrm{~m}$. The slope water is then advected along the coast some $80-130 \mathrm{~km}$ towards Port Stephens where the EAC typically diverges from the coast. This divergence is most intense near

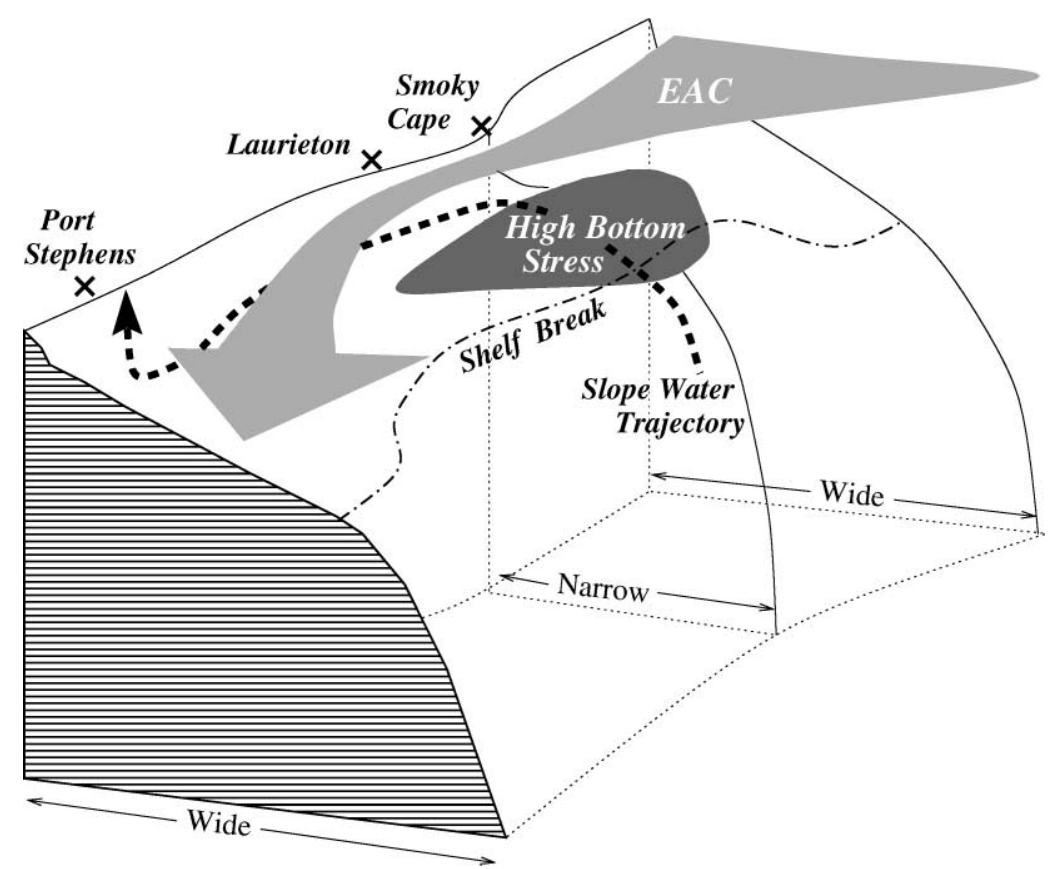

Fig. 14. Schematic diagram showing the proposed uplifting/upwelling mechanism between Smoky Cape and Port Stephens. 
the surface and the slope water is consequently upwelled to the surface by continuity. This mechanism is supported by the analysis of the dispersal of a passive concentration tracer initialised off Smoky Cape. This upwelling mechanism is represented schematically in Fig. 14, showing the proposed trajectory of the upwelled slope water in response to the EAC's alongshore adjustments. The proposed path of the upwelled slope water is qualitatively consistent with the observed chlorophyll distributions off Port Stephens presented by Hallegraeff and Jeffrey (1993). We suggest that upwelling through the mechanism described here is a regular, and perhaps seasonal feature of the EAC region, and is dependent on factors such as the proximity of the EAC to the shelf and the strength of the EAC that is known to have a strong seasonal cycle (Ridgway and Godfrey, 1997). Furthermore, the upwelling that is inferred by the SST image in Fig. 1 during November 1993 also seems to be consistent with the upwelling mechanism described in this study.

The dynamics of the proposed upwelling process is consistent with observations presented in the literature that have been made in the EAC region, as outlined below. The narrowing of the continental shelf near Laurieton was first suggested to be of local importance by Rochford (1975) to explain a series of observed upwellings. Moreover, details of Rochford's observations, such as the isotherm slopes, the alongshore spreading, and origin of upwelled water is consistent with the findings of this study. The mechanism is similar to that proposed by Boland (1979) and Blackburn and Cresswell (1993), who suggested that a BBL can be driven by currents associated with the EAC and its eddies in close proximity to the coast off Sydney. Furthermore, the cross-shore adjustments of the EAC are consistent with the observations of Tranter et al. (1986), whilst the argument that the EAC encounters regions of persistent, high bottom stress is supported by the inferred sediment entrainment along its path (Godfrey et al., 1980b).

The incidence of nutrient-rich slope water in the euphotic zone indicates that enhanced biological productivity could result, which provides an explanation for why Port Stephens has historically been susceptible to frequent algal blooms (Hallegraeff and Jeffrey, 1993). For the specific period that was considered in this study, namely January 1997, the proposed upwelling mechanism indicates that the Noctiluca bloom off Port Stephens probably formed as a result of EAC effects. This supports the findings of Ajani et al. (2000) and highlights the importance of oceanic nutrient sources in the development of algal blooms. Furthermore, this process may explain how nutrients are entrained into the mean EAC flow, explaining why high nutrient levels are commonly encountered off Sydney when EAC eddies encroach onto the continental shelf (Boland, 1979; Tranter et al., 1986; Cresswell, 1994).

\section{Acknowledgements}

This project was commissioned by the NSW EPA for the Ocean Nutrients and Phytoplankton Project, and was also supported by the Australian Research Council through grants to Jason Middleton and by an Australian Postgraduate Research Award to Peter Oke. Robert GardinerGarden, Tom Dennis and Patrick Marchesiello are thanked for their contributions to the development of the model configuration. The Australian National University is also acknowledged for making available the Fujitsu VPP300 Supercomputer for this research. The in situ current meter data was supplied by the NSW EPA and the temperature charts were supplied by 
the Oceanographic Data Centre of the Royal Australian Navy. The support of the National Greenhouse Advisory Committee is also acknowledged.

\section{References}

Ajani, P.A., Lee R.S., Pritchard, P.R., 2000. Phytoplankton responses to slope water intrusions off New South Wales, Australia, in preparation.

Blumberg, A.F., Kantha, L.H., 1985. Open boundary conditions for circulation models. Journal of Hydrological Engineering 111, 237-255.

Blumberg, A.F., Mellor, G.L., 1987. A description of a three-dimensional coastal ocean circulation model. In: Heaps, N. (Ed.), Three-Dimensional Coastal Ocean Models, Vol. 4. American Geophysical Union, Washington, DC, pp. 208.

Blackburn, S.I., Cresswell, G.R., 1993. A coccolithophorid bloom in Jervis Bay, Australia. Australian Journal of Marine Freshwater Research 44, 253-260.

Boland, F.M., Hamon, B.V., 1970. The East Australian Current, 1965-1968. Deep-Sea Research 17, 777-794.

Boland, F.M., 1979. A time series of expendable bathythermograph sections across the East Australian Current. Australian Journal of Marine and Freshwater Research 30, 303-313.

Church, J.A., Cresswell, G.R., 1986. Oceanographic features of Southeast Australian waters. CSIRO Marine Laboratories Internal Summary Report.

Cresswell, G.R., 1994. Nutrient enrichment of the Sydney continental shelf. Australian Journal of Marine and Freshwater Research 45, 677-691.

England, M.H., 1995. The age of water and ventilation timescales in a global ocean model. Journal of Physical Oceanography 25, 2755-2777.

Garrett, C., MacCready, P., Rhines, P., 1993. Boundary mixing and arrested Ekman layers: rotating stratified flow near a sloping boundary. Annual Reviews of Fluid Mechanics 25, 291-323.

Gibbs, M.T., Marchesiello, P., Middleton, J.H., 1997. Nutrient enrichment of Jervis Bay, Australia, during the massive 1992 coccolithophorid bloom. Marine and Freshwater Research 48, 473-478.

Gibbs, M.T., Middleton, J.H., Marchesiello, P., 1998. Baroclinic response of Sydney shelf waters to local wind and deep ocean forcing. Journal of Physical Oceanography 28, 178-190.

Godfrey, J.S., Cresswell, G.R., Boland, F.M., 1980a. Observations of low Richardson numbers and undercurrents near a front in the East Australian Current. Journal of Applied Meteorology 10, 301-307.

Godfrey, J.S., Cresswell, G.R., Golding, T.J., Pearce, A.F., 1980b. The separation of the East Australian Current. Journal of Physical Oceanography 10, 430-440.

Haidvogel, D.B., Wilkin, J.L., Young, R., 1991. A semi-spectral primitive equation ocean circulation model using sigma and orthogonal curvilinear coordinates. Journal of Computational Physics 94, 51-185.

Hallegraeff, G.M., Jeffrey, S.W., 1993. Annually recurrent diatom blooms in spring along the New South Wales Coast of Australia. Australian Marine and Freshwater Research 44, 325-334.

Leonard, B.P., Lock, A.P., Macvean, M.K., 1995. The Nivana scheme applied to one-dimensional advection. International Journal of Numerical Methods Heat Fluid Flow 15, 341-377.

Levitus, S., 1982. Climatological Atlas of the World Ocean. Technical Report 13, U.S. Department of Commerce, National Oceanographic and Atmospheric Administration, 173pp.

MacCready, P., Rhines, P., 1993. Slippery bottom boundary layers on a slope. Journal of Physical Oceanography 23, $5-22$.

Mellor, G.L., 1991. An equation of state for numerical models of Oceans and Estuaries. Journal of Atmospheric and Oceanic Technology 8, 609-611.

NOAA, 1988. NGDC data announcement 88-MG-02: Digital relief of the surface of the Earth, US Department of Commerce, NOAA, NGDC, Boulder, Colorado.

Oke, P.R., Middleton, J.H., 2000. Topographically induced upwelling off Eastern Australia. Journal of Physical Oceanography $30,512-531$. 
Orlanski, I., 1976. A simple boundary condition for unbounded hyperbolic flows. US Environmental Protection Agency Report. 150pp.

Palma, E.D., Matano, R.P., 1998. On the implementation of passive open boundary conditions for the Princeton Ocean Model: the barotropic mode. Journal of Geophysical Research 103, 1319-1341.

Pearce, A.F., 1983. Estimation of dynamic height from temperature profiles of the Tasman Sea. Australian Journal of Marine and Freshwater Research 34, 115-119.

Ridgway, K.R., Godfrey, J.S., 1997. Seasonal cycle of the East Australian Current. Journal of Geophysical Research 102, 22921-22936.

Rochford, D.J., 1975. Nutrient enrichment of east Australian coastal waters. II. Laurieton upwelling. Australian Journal of Marine and Freshwater Research 26, 233-243.

Tranter, D.J., Carpenter, D.J., Leech, G.S., 1986. The coastal enrichment effects of the East Australian Current eddy field. Deep-Sea Research 33, 1705-1728. 